\title{
Differential expression of NF-KB heterodimer RelA/p50 in human urothelial carcinoma
}

\author{
Sankari Durairajan ${ }^{1}$, Charles Emmanuel Jebaraj Walter ${ }^{\text {Corresp.., }}{ }^{1}$, Mary Divya Samuel ${ }^{2}$, Dinesh Palani ${ }^{1}$, Dicky \\ John Davis G ${ }^{3}$, George Priya Doss $C^{4}$, Sneha Pasupati ${ }^{4}$, Thanka Johnson ${ }^{5}$ \\ 1 Department of Biotechnology, Sri Ramachandra Medical College and Research Institute (Deemed to be University), Chennai, India \\ 2 Manipal Institute of Regenerative Medicine, Manipal Academy of Higher Education (formerly Manipal University), Manipal, India \\ 3 Department of Bioinformatics, Sri Ramachandra Medical College and Research Institute (Deemed to be University), Chennai, India \\ 4 Department of Integrative Biology, School of Biosciences and Technology, Vellore Institute of Technology, Vellore, Tamilnadu, India \\ 5 Department of Pathology, Sri Ramachandra Medical College and Research Institute (Deemed to be University), Chennai, India \\ Corresponding Author: Charles Emmanuel Jebaraj Walter \\ Email address: cejwalter@sriramachandra.edu.in
}

Background. Urothelial Carcinoma (UC) is the fifth most common malignancy that accounts for $5 \%$ of all cancers. Diagnostic markers that predict UC progressions are inadequate. NF-kB contributes towards disease progression upon constitutive activation in many solid tumors. The nuclear localization of NF-kB indicates increased transcriptional activity while cytoplasmic localization indicates the inactive protein repository that can be utilized readily by a malignant cell. This study delineates the nuclear and cytoplasmic differential expression of NF-kB heterodimers in UC progression.

Methods. The involvement of the NF-KB proteins in UC was analyzed in silico using cytoscape. The expression of NF-kB heterodimers was analyzed by immunohistochemistry.

Results. PINA4MS app in cytoscape revealed over expression of RelA and suppression of NF-kB1 (p50 precursor) in UC whereas the expression of NF-kB target proteins remained unhindered.

Immunohistochemical localization showed nuclear RelA/p50 in low grade UC whereas in high grade only RelA expression was observed. Conversely, cytoplasmic expression of RelA/p50 remained extensive across high and low grade UC tissues $(p<0.005)$. RelA nuclear and cytoplasmic expression $(p<0.005)$ was directly proportional to the disease progression. In our study, some of the high grade UC tissues with squamous differentiation and muscle invasion had extensive nuclear p50 localization. The phenomenon of RelA/p50 expression seen increased in low grade UC than high grade UC might be due to their interaction with other members of NF-kB family of proteins. Thus, NF-kB RelA/p50 differential expression may play a unique role in UC pathogenesis and can serve as a biomarker for diagnosis. 


\section{Differential expression of NF-кB heterodimer RelA/p50 in human urothelial carcinoma}

\section{AUTHOR NAMES \& AFFILIATION}

3 Sankari Durairajan a, 1

4 Charles Emmanuel Jebaraj Walter a, 1, $\square$

5 Mary Divya Samuel a, b

6 Dinesh Palani a,

7 Dicky John Davis $\mathrm{G}^{\mathrm{c}}$

8 George Priya Doss $\mathrm{C}^{\mathrm{d}}$

9 Sneha Pasupati d

10 Thanka Johnson $^{\mathrm{e}}$

111 These authors share first authorship

12 a Department of Biotechnology, Sri Ramachandra Medical College and Research Institute

13 (Deemed to be University), Chennai, India

b Manipal Institute of Regenerative Medicine, Manipal Academy of Higher Education

c Department of Bioinformatics, Sri Ramachandra Medical College and Research Institute

(Deemed to be University), Chennai, India

d Department of Integrative Biology, School of Biosciences and Technology, Vellore Institute of Technology, Vellore, Tamilnadu, India

e Department of Pathology, Sri Ramachandra Medical College and Research Institute

Corresponding author at Department of Biotechnology, Sri Ramachandra Medical College and Research Institute (Deemed to be University), Chennai, India E-mail address: cejwalter@sriramachandra.edu.in (C E Jebaraj Walter) Telephone.+91-44-45928602. ORCID \#. 0000-0003-1370-5205 


\section{Differential expression of NF-кB heterodimer RelA/p50 in human urothelial carcinoma}

\section{Abstract}

Background. Urothelial Carcinoma (UC) is the fifth most common malignancy that accounts for $5 \%$ of all cancers. Diagnostic markers that predict UC progressions are inadequate. NF- $\mathrm{B}$ contributes towards disease progression upon constitutive activation in many solid tumors. The nuclear localization of NF- $\mathrm{B}$ indicates increased transcriptional activity while cytoplasmic localization indicates the inactive protein repository that can be utilized readily by a malignant cell. This study delineates the nuclear and cytoplasmic differential expression of NF- $\mathrm{BB}$ heterodimers in UC progression.

Methods. The involvement of the NF- $\mathrm{B}$ proteins in UC was analyzed in silico using cytoscape. The expression of NF- $\kappa \mathrm{B}$ heterodimers was analyzed by immunohistochemistry.

Results. PINA4MS app in cytoscape revealed over expression of RelA and suppression of NF$\kappa \mathrm{B} 1$ (p50 precursor) in $\mathrm{UC}$ whereas the expression of $\mathrm{NF}-\kappa \mathrm{B}$ target proteins remained unhindered. Immunohistochemical localization showed nuclear RelA/p50 in low grade UC whereas in high grade only RelA expression was observed. Conversely, cytoplasmic expression of RelA/p50 remained extensive across high and low grade UC tissues $(\mathrm{p}<0.005)$. RelA nuclear and cytoplasmic expression $(\mathrm{p}<0.005)$ was directly proportional to the disease progression. In our study, some of the high grade UC tissues with squamous differentiation and muscle invasion had extensive nuclear p50 localization. The phenomenon of RelA/p50 expression seen increased in low grade UC than high grade UC might be due to their interaction with other members of $\mathrm{NF}-\kappa \mathrm{B}$ family of proteins. Thus, NF- $\kappa \mathrm{B}$ RelA/p50 differential expression may play a unique role in UC pathogenesis and can serve as a biomarker for diagnosis.

\section{Introduction}

In industrialized countries, Urothelial Carcinoma (UC) is the fifth most common cancer and second most common genitourinary tract cancer (Schulz 2006; Lee et al., 2014). UC classification has an important role in determining treatment for patients and their prognosis (Öztürk 2015). According to WHO grading in 2004, there are papilloma, papillary urothelial neoplasm of low malignant potential, low-grade UC and high-grade UC (Babjuk et al., 2017). The extent of tumor tissue invasion is defined by the stages Ta, T1, T2, T3 and T4. Most stages 
60

61

62

63

64

65

66

67

comprising Ta and T1 are composed of non-muscle invasive tumor confined to only the epithelium and lamina propria. Muscle invasive tumors invade the detrusor smooth muscle or beyond and they belong to the stages T2 to T4 (Kobayashi et al., 2014). Since bladder neoplasm is morphologically and genetically heterogeneous, it is important to differentiate these lesions as their treatment outcomes differ (Hodges et al., 2010). Low-grade UC with Ta and T1 stages require long term treatment and surveillance while high-grade T1-T4 stages would require meticulous strategizing for effective treatment inhibiting metastasis (Abol-Enein 2008; Bellmunt et al., 2014; Miller et al., 2016). Hence biomarkers that could predict UC progression is warranted.

Nuclear factor kappa B (NF- $\kappa \mathrm{B})$ transcription factor is an assembly of protein subunits as heterodimers that bind to a specific region on genes called the $\kappa \mathrm{B}$ site for its function. Each dimer: RelA/p50; RelA/p52, RelB/p50, RelB/p52, RelA/RelB and p50/p52 have distinct function in the cell acting upon specific stimuli. Upon induction, they act to modulate the immune system, inflammation, angiogenesis, survival and proliferation of cells (Gilmore, 2006). These effects are brought about by orchestrating more than 200 genes by the canonical pathway (classical) or the non-canonical pathway (alternate) as illustrated in Fig. 1. These important genes are tightly regulated under normal conditions, however, constitutive activation of NF- $\kappa$ B pathway occurs during tumorigenesis leading to aberrant expression of many target proteins (Meteoglu et al., 2008). Like other solid tumors, UC usually has a poorly understood association with an inflammatory-phenotype regulated by pro-inflammatory cytokine secretion (Masilamoni et al., 2006; Lee et al., 2012). NF- $\kappa B$ being the major inflammatory transcription factor, its role in UC needs exploration (Mukherjee et al., 2015). All NF-אB heterodimers act together for gene transcription while some homodimers of NF- $\kappa \mathrm{B}$ are repressors of transcription. Hence we hypothesize analyzing the nuclear and cytoplasmic localization of the heterodimers in low and high grade UC will reveal the degree of transcriptional activation and thus the disease progression and would serve as novel biomarkers.

\section{Materials and methods}

\section{Cytoscape analysis of NF-kB heterodimers $(\operatorname{RelA} / \mathbf{p 5 0})$}


$88 \mathrm{NF}-\kappa \mathrm{B}$ family of proteins and their representative target protein list was created by text mining 89 of literature and from KEGG database for NF-kB signaling pathway of Homo sapiens (04064).

90 Uniprot IDs (provided as supplemental files, datasets) were identified for the list of proteins and analyzed in Cytoscape. This tool helps in visualization and analysis of the tissue specific expression data, RNA sequence data and interactions between/within multiple protein datasets. Protein Interaction Network Analysis for Multiple Sets (PINA4MS) app is a plug-in for cytoscape that uses protein interaction data from six public databases that are curated manually: IntAct, MINT, BioGRID, DIP, HPRD and MIPS MPact data, thus increasing the efficiency of the tool (Cowley et al., 2003; Shannon et al., 2003). The physical interactions among proteins of interest were retrieved from the Protein Interaction Network Analysis (PINA) platform, and kinase-substrate relationships were downloaded from the PhosphoSitePlus database.

Using the UniProt IDs as input we utilized the pre-existing UC tissue specific expression data set in the app to analyze the NF- $\mathrm{BB}$ family of proteins and their targets. Comparative analysis was performed with those proteins expressed on normal tissues and urothelial carcinoma tissues using PINA4MS app. Thresholds and limits (protein interactions only with the range 0.01-2; inter and intra spread value was set to 1 and circular cluster layout was chosen) set as default parameters of the tool were used while constructing the figure. This app uses the hypergeometric test to identify and eliminate the false discovery rate. It identifies the overrepresented terms with a correction for multiple testing using false discovery rate (the P-value $<0.05$ was adjusted). The hypergeometric test was applied to test statistical enrichment of identified KEGG and reactome pathways and the $P$ values were corrected for multiple comparisons using the Benjamini and Hochberg method. The output file of each tool was created and the functional enrichment analyses were performed on an SGE cluster using GOstats. For pathway enrichment analysis, the KEGG Orthology Based Annotation System (KOBAS) was used. The bubble diameter of the protein analyzed is representative of the degree of protein expression.

\section{Urothelial tissues}

The study was designed with 121 cases under two main groups: (i) Normal tissues from subjects with no malignancy but presented with an inflammatory condition of the bladder; $n=60$ and (ii) Urothelial carcinoma of low grade and high grade; $n=61$. The retrospective study design waived 
117 the need for obtaining informed consent from the patients, however the Institutional Ethical

118 Committee of Sri Ramachandra Medical College and Research Institute (Deemed to be

119 University), Chennai, India reviewed and accepted the study approving the use of FFPE tissues

120 deposited at Sri Ramachandra Medical Centre from the year 2008 for this retrospective study

$121(\mathrm{CSP} / 14 / \mathrm{FEB} / 33 / 25)$.

\section{Statistical analysis}

123 Clinicopathological features were compared between the normal group and cancer group of

124 patients. Low and high grades of UC were also compared to derive useful statistical associations

125 using Mann Whitney U test and Fisher's exact test. Pearson's Chi-Square test was used for

126 assessing differential expression of NF- $\mathrm{B}$ heterodimers between the normal and cancer group.

127 Any $\mathrm{p}$ value $<0.05$ was considered to be statistically significant. All the statistical analyses were

128 performed using IBM SPSS v23.

129

130

131

132

133

134

135

136

137

138

139

140

141

142

143

144

\section{Immunohistochemical analysis}

Urothelial tissues fixed in $10 \%$ buffered formalin for $24 \mathrm{~h}$ at $4{ }^{\circ} \mathrm{C}$ were processed and embedded in paraffin as tissue blocks. FFPE tissue sections with $4 \mu \mathrm{M}$ thickness were deparaffinized, rehydrated and incubated in Citrate buffer at $\mathrm{pH} 6.0$ for 30 min under pressure for antigen retrieval. Once when the tissue sections were brought to ambient temperature, endogenous peroxidase was quenched using hydrogen peroxide (10\%) for $20 \mathrm{~min}$. The sections were further washed twice with tris buffered saline (TBS) at $\mathrm{pH} 7.3$ and blocked with normal goat serum (Biolegend, USA) to reduce non-specific background staining. Tissue sections were incubated overnight with a rabbit polyclonal IgG anti-NF-кB p65 antibody (622602, Biolegend, USA) and with rabbit polyclonal IgG anti-NF-кB p50 antibody (sc-7178, Santa Cruz, USA) respectively, at a dilution of 1:200 each. Sections were then washed in TBS and incubated with HRP conjugated secondary antibody (goat anti rabbit IgG-HRP: sc-2004, Santa Cruz, USA) for $2 \mathrm{~h}$ and visualized using 3, 3'-diaminobenzidine (Sigma, USA). Finally, the sections were counterstained with Mayer's hematoxylin, dehydrated and cover-slipped. Meteoglu et al. (2008) method was followed with slight modifications. The lymphocytes in the UC tissue sections were found to be positive for the NF- $\kappa \mathrm{B}$ heterodimers (RelA/p50) and hence served as positive controls. Further, 
145 normal urothelium devoid of blood vessels served as negative control (No primary antibody, 146 reagent control).

147 The immunohistochemical staining was documented using Olympus BX43 microscope with 148 QImaging Micropublisher 3.3 RTV camera and QCapture Pro 7 software (Canada). Each

149

150

151

152

153

154

155

156

157

158

159

160

161

162

163

164

165

166

167

168

169

170

171

172

173

section was assessed for the immunoperoxidase staining and scored by a pathologist. The scoring includes RelA and p50 nuclear and cytoplasmic staining positivity. RelA and p50 staining in the nucleus and cytoplasm were scored as follows (i) absence of staining (no or non-specific), (ii) low $(<20 \%)$, (iii) moderate (21- 60\%) and (iv) extensive ( $>60 \%)$ staining.

\section{Results}

\section{In silico differential expression of $\mathrm{NF}-\kappa \mathrm{B}$ family of proteins and their targets in $\mathrm{UC}$ and} normal urothelium

Cytoscape app PINA4MS extracted the differentially expressed proteins of normal and UC

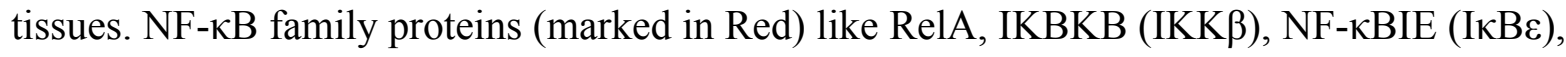
IKBKG (NEMO), CHUK (IKK $\alpha$ ) were over expressed in UC when compared to normal

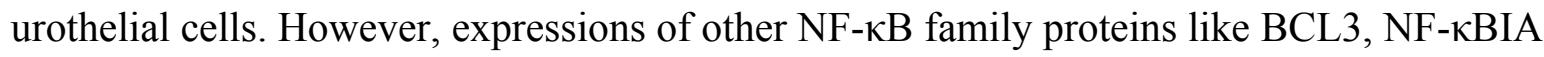

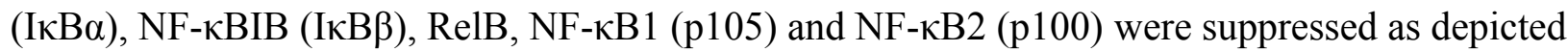
by the diameter of the bubble (Fig. 2, 3). The NF- $\kappa$ B target proteins (marked in Green), like CFLAR (c-FLIP), TRAF2, XIAP, MYC, BIRC3, TRAF1, BCL2, CCND1, IL8, ICAM1 and VCAM1 showed altered expression (Fig. 2, 3). These proteins are either direct or indirect targets of NF- $\kappa$ B signal transduction. Of the target proteins, VEGF-A, SOD2, and PTGS2 (COX2) showed over expression, however, TRAF2, CFLAR (c-FLIP), XIAP, BIRC3 (cIAP-2), BIRC2 (cIAP-1), MYC and BAD proteins showed homogenous expressions while CCL4 (MIP-1 $\beta$ ), CCND1 (Cyclin D1), ICAM1, BCL2, MMP9 and TRAF9 proteins showed a more suppressed state (Fig. 2, 3). The app resulted in a direct association between RelA and NF- $\mathrm{kB} 1$ (p50 precursor) with a difference in their expression levels between UC and normal tissues. Hence, the localization of RelA/ p50 heterodimers was further analyzed using immunohistochemistry in UC and normal urothelium.

\section{Clinicopathological correlations with NF-кB heterodimer expression in UC and normal} urothelium 
174 The clinicopathological parameters like age, gender, tumor size and grades of UC were assessed

175 to find the significance between nuclear and cytoplasmic localization of NF- $\kappa \mathrm{B}$ heterodimers.

176 The age of patients in the normal group ranged from 20 to 79 years and those in the cancer group

177 ranged from 18 to 88 years. It was a heterogeneous population consisting of 32 males and 28

178 females in the normal group whereas 49 males and 12 females in cancer group. UC occurrence

179 was higher in the age category of 61 to 70 years and found to have a high incidence in the male

180 population with a statistical significance of $\mathrm{p}<0.05$. Comparison of tumor size, grades had high

181 significance $(\mathrm{p}<0.005)$ and revealed significant association with RelA nuclear $(\mathrm{p}<0.005)$ and

182 cytoplasmic localization $(\mathrm{p}<0.005)$. However, there was no association with p50 nuclear

183 localization $(\mathrm{p}>0.05)$ but there was a significant association with the cytoplasmic expression $(p$

$184<0.05)$. Those cases that had muscle invasive areas showed differential uptake of the NF- $\kappa B$

185 subunits irrespective of grade.

186 The nuclear expression of RelA when compared between normal and UC groups by Pearson's

187 chi-square test $\left(\chi^{2}\right)$ revealed a strong association with UC and nuclear localization (Table 1).

188 Comparison of the high and low grades of UC by Fisher's exact test showed no association with

189 RelA nuclear localization and UC grades (Table 2). The cytoplasmic expression of RelA was

190 compared with normal and UC group by Pearson's chi-square test and it revealed a significant

191 association with UC (Table 3). Comparing high and low grades of UC and the cytoplasmic

192 localization of RelA by Fisher's exact test revealed significant associations for RelA cytoplasmic

193 localization (Table 4). Similarly, the nuclear expression of p50 was compared between normal

194 and UC groups by Pearson's chi square test which had significant associations (Table 1) with UC

195 and nuclear localization. Comparison of high and low grades of UC by Fisher's exact test

196 revealed no significant associations with p50 nuclear localization and UC grades (Table 2).

197 When cytoplasmic expression of p50 was compared in normal and UC group by Pearson's chi-

198 square test it exhibited high statistical significance in UC (Table 3). Comparing the cytoplasmic

199 expression of p50 within high and low grades of UC using Fisher's exact test, showed significant

200 association for p50 cytoplasmic localization (Table 4). The normal urothelium had no significant

201 associations in the localization of the NF- $\kappa$ B heterodimers. The inflammatory regions had weak

202 to moderately stained heterodimers in the cytoplasm and the nucleus had only negligible

203 staining, unlike neoplastic cells (Tables 1,3). 
204 Differential expression of NF-кB subunits in high grade UC

205 The expression of RelA and p50 are described based on the grade and stage of UC for clarity.

206 H\&E staining revealed histology of a non-invasive high grade UC with Ta stage (Fig. 4A). RelA

207 expression in high grade UC at Ta stage had most of the urothelial cells positive for nuclear

208 expression along with extensive cytoplasmic expression (Fig. 4B). However, nuclear staining

209 was absent for p50 in high grade UC at Ta stage but all urothelial cells had moderate to extensive

210 cytoplasmic expression (Fig. 4C). The focal areas of squamous cell differentiation in high grade

211 UC (5\%) also showed nuclear positivity (Fig. 4D). RelA nuclear expression in high grade UC at

212 T1 stage was low whereas its cytoplasmic expression remained extensive (Fig. 4E). In high grade

213 UC at T1 stage, p50 expression was moderately positive in the nucleus with extensive

214 cytoplasmic expression (Fig. 4F). H\&E staining revealed the histology of high grade invasive

215 UC with focal squamous differentiation and muscle invasion at T2b stage (Fig. 4G). Nuclear

216 RelA expression in high grade UC at T2 stage was low and the cytoplasmic expression was

217 moderate to extensive (Fig. 4H). Nuclear p50 expression was low but had extensive cytoplasmic

218 staining in T2 stage of UC. Muscle invasive areas and regions with squamous differentiation had

219 intense staining of p50 subunit (Fig. 4I). High grade UC at T3 stage showed moderate expression

220 of RelA in the nucleus and cytoplasm. However, p50 nuclear staining was absent and showed

221 moderate cytoplasmic positivity.

222

223

224

225

226

227

228

229

230

231

232

233

\section{NF-кB heterodimer expression varies in low grade UC and normal urothelium}

H\&E staining revealed histology of low grade papillary UC at Ta stage (Fig. 5A). The expression of NF- $\mathrm{kB}$ heterodimers was prominent with extensive nuclear and cytoplasmic expression of RelA (Fig. 5B). However, nuclear expression of p50 in low grade UC at Ta stage was observed along with extensive cytoplasmic expression (Fig. 5C). H\&E staining revealed tumor histology suggestive of low grade papillary UC with T1 stage (Fig. 5D). Also, low grade papillary UC at T1 stage had extensive nuclear staining of RelA with equivalent expression in the cytoplasm (Fig. 5E). Nuclear expression of p50 in low grade UC at T1 stage was absent but it expressed moderate to extensive cytoplasmic staining (Fig. 5F). RelA/p50 subunits had negligible nuclear positivity and low to moderate cytoplasmic positivity in normal urothelial tissues. The regions of inflammation had some prominent nuclear positive cells of RelA/p50 subunits but they did not show any significance. However, the cytoplasm showed a difference in 
234 the staining intensity for both subunits when compared to their nuclear staining which was

235 restricted to cells with inflammation (Fig. 5H, 5I).

\section{Discussion}

237 The role of NF- $\kappa$ B pathway proteins in the development and progression of UC is still

238

239

240

241

242

243

244

245

246

247

248

249

250

251

252

253

254

255

256

257

258

259

260

261

262

263

unexplored. Constitutively active NF- $\mathrm{KB}$ tends to protect the cells from apoptosis and cross-talks with other pathways that are capable of retaining proliferating cells viable during the process of

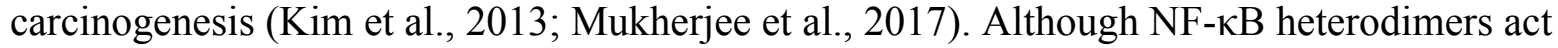
together for gene activation, homodimers of p50 repress transcription by binding to DNA. Furthermore, there are other binding partners for both the subunits to elicit their function. The degree of transcriptional activation which denotes UC progression can be understood from the variations observed in their nuclear/cytoplasmic expression. NF- $\mathrm{B}$ nuclear localization indicates increased transcriptional activity and cytoplasmic localization indicates the inactive protein repository that can be utilized readily by a malignant cell. Differentiating these neoplasms is crucial as they can influence treatment outcomes (Hodges et al., 2010). This study analyzing the nuclear and cytoplasmic localization of the heterodimers in low and high grade UC unravels the disease progression.

In silico analysis was performed to assess the expression of $\mathrm{NF}-\kappa \mathrm{B}$ family of proteins and their target proteins using the cytoscape app PINA4MS. The app virtually assessed the tissue specific protein expression utilizing the data deposited in six different databases. A list of NF- $\kappa \mathrm{B}$ family of proteins with their target proteins used as inputs showed their expression in normal and UC. Our results revealed suppression of $\mathrm{NF}-\kappa \mathrm{B} 1$ (p50 precursor), NF- $\mathrm{kB} 2$ (p52 precursor) and RelB in urothelial tumor tissue (Fig. 2). We also found a reduction in the expression of CHUK (IKK $\alpha$ ) and similar regulatory proteins of NF- $\mathrm{B}$ in the tumor cells in comparison to normal (Fig. 3). $\mathrm{NF}-\kappa \mathrm{BIE}(\mathrm{I} \kappa \mathrm{B} \varepsilon)$ and $\mathrm{I} \kappa \mathrm{BKB}(\mathrm{IKK} \beta)$ are the upstream molecules that showed over expression in tumor tissue when compared to normal urothelial tissue. These results convey that the dysregulated upstream molecules of the NF- $\kappa B$ contribute to the constitutive activation of the $\mathrm{NF}-\kappa \mathrm{B}$ pathway resulting in an over expression of NF- $\kappa \mathrm{B}$ downstream target proteins to enrich the tumor microenvironment convincing earlier studies of Slattery et al., 2018. Accordingly, most of the NF- $\kappa \mathrm{B}$ direct target proteins like XIAP, BCL3, TRAF2, BIRC3, RelB, SOD2, CFLAR or the indirect target proteins like MYC, BAD, PTGS2/COX2, CxCL2, VEGFA, 
264 VCAM1, ICAM1 found to be expressed in normal urothelium where seen selectively expressed 265 or suppressed in the case of UC (Fig. 2). Our study revealed over expression of pro-survival or 266 pro-proliferative factors (TRAF-1, TRAF-2, CFLAR, XIAP, BIRC2, BIRC3, VEGF-A, BAFF) 267 and suppression of NF- $\kappa B$ inhibitory factors (NF- $\kappa B 1 E, N F-\kappa B 1, N F-\kappa B 1 A, N F-\kappa B 1 B)$ in UC.

268

PINA4MS app in cytoscape revealed involvement of NF- $\mathrm{kB}$ direct or indirect target proteins that contribute to UC carcinogenesis by modulating the steps of carcinogenesis (oncogenic control, cellular transformation, proliferation, invasion, angiogenesis and metastasis) as illustrated in Fig.

1. The expression of NF- $\mathrm{kB}$ target proteins remained unhindered whereas over expression of RelA and suppression of NF- $\mathrm{kB} 1$ (p50 precursor) was observed in UC which was further analyzed by immunohistochemistry.

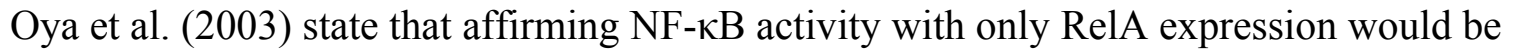
insufficient to conclude a finding since the binding of target genes is brought about by both subunits. However, many cancer studies have assessed the involvement of the RelA subunit alone or in combination with other subunits like RelB, NF-kB2, c-Rel, etc. Nonetheless, outcome of the studies that methodically examined RelA and p50 have reported altered expression with an impact on recurrence and survival (Jenkins et al., 2007; Annunziata et al., 2010; Wu et al., 2015). Our study has analyzed the expression of NF-kB subunits, RelA/p50 using immunohistochemistry hypothesizing a difference in their expression as supported by the preliminary in silico results. The clinicopathological parameters such as age, gender, tumor size, stage and grade were assessed with the localization of the RelA/p50 heterodimers. Geriatric males had the highest incidence of UC which can be attributed to an occupational hazard and/or habit and/or lifestyle which was not assessed in this study. The association of tumor size with nuclear localization had significance with RelA $(\mathrm{p}<0.05)$ but not with $\mathrm{p} 50$ subunit $(\mathrm{p}=0.655)$.

Our observation on the expression of RelA subunit in UC was similar to the pattern reported by Levidou et al. (2008) while the clinical significance of our study was the expression of NF- $\mathrm{KB}$ p50 subunit. The heterodimers are retained in the cytoplasm in their inactive form which upon activation translocates to the nucleus for gene transcription. At a given instance not all the inactive heterodimers are capable of getting activated upon stimulation for translocation since this step is tightly regulated as shown by King et al., 2011. However, the amount of inactive heterodimers in the cytoplasm shows the capacity of the cell to keep the signaling cascade active. 
294 This reflects the potential of over expressed NF- $\kappa$ B to manipulate UC aggressiveness and or 295 progression, hence considering its expression seemed rational. Accordingly, we observed 296 moderate to extensive cytoplasmic localization of RelA and p50 in all low and high grades of UC

297 (Ta, T1, T2 and T3) investigated (Fig. 4). RelA was seen localized in the nucleus of all high 298 grade stages of UC but only a few cases localized p50 (specifically T1, T2) which portrays the 299 differential expression of NF-kB heterodimers in UC. A similar pattern was observed in renal cell carcinoma (Sweeney et al., 2004) where the expression of p50 in the nucleus was seen decreased. The nuclear expression of RelA and p50 in low grade Ta was positive and their expression was comparable though the p50 expression was not extensive like RelA (Table 1,2). RelA was seen localized in the nucleus of all low grade, stages (Ta, T1) of UC conversely NFкB p50 subunit was seen localized only in Ta stage UC (Fig. 5). Our study revealed that those tissues with muscle invasion and squamous differentiation had altered expression of $\mathrm{p} 50$. In intraepithelial neoplasia, a precancerous condition of the prostate also showed increased p50 subunit with other binding partners like RelB and p52 over the classic heterodimer expression supporting disease progression (Lessard et al., 2006; Degoricija et al., 2014). In our study, we have not assessed the expression of RelB or p52 but the pattern of RelA/p50 heterodimer expression studied was similar to Lessard et al. (2006) as reported in prostate cancer. The increased nuclear localization seen in the low grade UC than high grade UC is suggestive of the contribution of NF- $\mathrm{kB}$ heterodimer in the initial stages of UC pathogenesis.

Nuclear expression of $\mathrm{p} 50$ homodimers can be independent of RelA since they can form complexes with other proteins like CBP, Bcl-3, histone deacetylase 1 (HDAC-1) and p300 for DNA binding to initiate or repress gene transcription based on the binding partner (Karst et al., 2009). Hence the involvement of $\mathrm{p} 50$ in UC is perhaps independent of the IKB regulation and or in combination with other transcriptional activators for gene transcription. In normal conditions, the homodimers of p50 are reported to be repressors and they are up-regulated for inhibiting the NF- $\mathrm{kB}$ signaling (Annunziata et al., 2010). In UC, we speculate that this inhibitory mechanism is dysregulated. In our study lymphocytes served as in-built controls of RelA/p50 staining (Fig. 4C, $5 \mathrm{H})$. Tumor-associated macrophages are known to show nuclear p50 positivity attributing to anti-tumor response suppression (Saccani et al., 2006; Annunziata et al., 2010) and many investigations state the presence of tumor infiltrative macrophages with poor prognosis (Szebeni et al., 2017). The significance of lymphocytes showing NF- $\mathrm{kB}$ heterodimers positive staining in 
$325 \mathrm{UC}$ is unknown. Muscle invasion and squamous differentiation are indicators of poor prognosis

326 with adverse outcome in UC (Amin, 2009; Lee et al., 2014). Selective nuclear localization of p50

327 in certain regions of UC tissues in our study warrants further investigation on the actual

328 mechanism of action in UC pathogenesis. Annunziata et al. (2010) have associated NF- $\kappa$ B p50

329 with poor survival in ovarian cancer patients post-treatment. Similarly, this study on UC, that

330 demonstrates differential p50 expression is suggestive of its participation in disease progression

331 and hence targeting it would help patient's early diagnosis and as a novel biomarker.

\section{Conclusion}

333 Differential nuclear expression of the NF- $\mathrm{B}$ B subunits RelA/p50 poses important questions on 334 their functions in UC. RelA must dimerize for DNA binding activity as they lack the DNA

335 binding domain. From this study, it becomes evident that RelA has a partner that allows it to 336 transcribe the target genes. The lack of extensive nuclear p50 suggests that RelA translocates 337 with another binding partner instead of p50. Among the NF- $\kappa$ B family of proteins identifying 338 the RelA preferred binding partner during UC progression will shed some light on the role of 339 RelA in the progression of UC. In addition, preventing the migration of RelA by blocking the 340 interaction of its preferred nuclear partner may abrogate the progression of UC. Investigating the 341 significant cytoplasmic expression of p50 similar to RelA across UC tissues when it is not the 342 preferred binding partner will also add some interesting facts to the NF- $\kappa B$ mystery in UC.

343 Altogether, this phenomenon could be contemplated as the capacity of the neoplastic cell to 344 activate the over expressed cytoplasmic NF- $\kappa B$ constitutively for tumor promotion, addressing 345 these critical questions would help in early diagnosis, aid in better treatment and management of 346 UC.

\section{Acknowledgements}

348 The authors thank Dr. Caven S Mcloughlin, Fulbright Specialist, Kent State University, USA for 349 his suggestions. The authors acknowledge the assistance in statistics provided by T. Gayathiri, 350 Senior Lecturer, Department of Community Medicine, Sri Ramachandra Medical College and 351 Research Institute (Deemed to be University), India.

352 Abbreviations 
353 BAD

354 Bcl-2

355 BCL3

356 BCR

357 BioGRID

358 BIRC3/cIAP

359 CBP

360 CCL4

361 CCND1/Cyclin D1

362 CFLAR/c-FLIP

$363 \mathrm{CHUK} / \mathrm{IKK} \alpha$

364

365

366

367

368

369

370

371 HPRD

372 HRP

373 ICAM1

374 IL-8

375 IntAct

$376 \quad \mathrm{I} \kappa \mathrm{B} \beta$

377 IKK $\beta$

378 MINT

379 MIPS-MPact 380
Bcl-2-associated agonist of cell death

Apoptosis regulator $\mathrm{Bcl}-2$

B-cell lymphoma 3 protein

B-cell receptor

Biological General Repository for Interaction Datasets

Baculoviral IAP (inhibitors of apoptosis) repeat-containing protein 3

CAMP Response Element Binding (CREB) - protein

C-C motif chemokine 4

G1/S-specific cyclin-D1

CASP8 and FADD-like apoptosis regulator

Conserved helix-loop-helix ubiquitous kinase/inhibitor of nuclear factor$\kappa \mathrm{B}$ kinase $\alpha$

Macrophage colony-stimulating factor 1

Database of Interacting Proteins

Formalin fixed paraffin embedded

Gene Ontology Statistics

Haematoxylin and Eosin staining

Hypoxia inducing factor $\alpha$

Human Protein Reference Database

Horse raddish peroxidase

Intercellular adhesion molecule 1

Interleukin-8

Molecular interaction database

Inhibitor of nuclear factor kappa B $\beta$

Inhibitor of nuclear factor $\kappa \mathrm{B}$ kinase $\beta$

Molecular INTeraction database

Munich Information Center for Protein Sequences- MIPS Mammalian Protein-Protein Interaction Database 


\begin{tabular}{|c|c|c|}
\hline 381 & MMP9 & Matrix metalloproteinase 9 \\
\hline 382 & MYC & Myelocytomatosis virus oncogene cellular homolog \\
\hline 383 & NEMO & NF- $\kappa$ B Essential Modulator \\
\hline 384 & NF-кB & Nuclear factor-kappa B \\
\hline 385 & $\mathrm{NF}-\kappa \mathrm{B} 1$ & Precursor p105 and processed p50 \\
\hline 386 & $\mathrm{NF}-\kappa \mathrm{B} 2$ & Precursor p100 and processed p52 \\
\hline 387 & NIK & $N F-\kappa B$ inducing kinase \\
\hline 388 & PINA4MS & Protein Interaction Network Analysis For Multiple Sets \\
\hline 389 & PTGS2/COX2 & Prostaglandin G/H synthase 2 \\
\hline 390 & pTIS & Carcinoma in situ \\
\hline 391 & RelA & V-Rel reticuloendotheliosis viral oncogene homolog A \\
\hline 392 & RelB & V-Rel reticuloendotheliosis viral oncogene homolog B \\
\hline 393 & SGE & Sun Grid Engine \\
\hline 394 & SOD2 & Superoxide dismutase 2 \\
\hline 395 & TNF & Tumor necrosis factor \\
\hline 396 & TP53 & Cellular tumor antigen p53 \\
\hline 397 & TLRs & Toll like receptors \\
\hline 398 & TCR & T-cell receptor \\
\hline 399 & TRAF2 & TNF receptor-associated factor 2 \\
\hline 400 & VCAM & Vascular cell adhesion protein \\
\hline 401 & VEGF-A & Vascular endothelial growth factor A \\
\hline 402 & XIAP & E3 ubiquitin-protein ligase. \\
\hline 103 & References & \\
\hline
\end{tabular}

404 Abol-Enein H. 2008. Infection: is it a cause of bladder cancer? Scandinavian Journal of Urology 405 and Nephrology Supplementum 42:79-84 DOI: 10.1080/03008880802325309 
406

407

408

409

410

411

412

413

414

415

416

417

418

419

420

421

422

423

424

425

426

427

428

429

430

431

Amin MB. 2009. Histological variants of urothelial carcinoma: diagnostic, therapeutic and prognostic implications. Modern Pathology 22:S96-S118 DOI: 10.1038/modpathol.2009.26

Annunziata CM, Stavnes HT, Kleinberg L, Berner A, Hernandez LF, Birrer MJ, Steinberg SM, Davidson B, Kohn EC.2010. Nuclear factor $\kappa$ B transcription factors are co-expressed and convey a poor outcome in ovarian cancer. Cancer 116:3276-3284 DOI: 10.1002/cncr.25190

Babjuk M, Böhle A, Burger M, Capoun O, Cohen D, Compérat EM, Hernández V, Kaasinen E, Palou J, Rouprêt M, van Rhijn BAS, Shariat SF, Soukup V, Sylvester RJ, Zigeuner R. 2017. EAU guidelines on non-muscle-invasive urothelial carcinoma of the bladder: Update 2016. European Urology 71:447-461 DOI: 10.1016/j.eururo.2016.05.041

Bellmunt J, Orsola A, Leow JJ, Wiegel T, De Santis M, Horwich A. 2014. Bladder cancer: ESMO practice guidelines for diagnosis, treatment and follow-up. Annals of Oncology 25:40-48 DOI: 10.1093/annonc/mdu223

Cowley MJ, Pinese M, Kassahn KS, Waddell N, Pearson JV, Grimmond SM, Biankin AV, Hautaniemi S and Wu J. 2012. PINA v2.0: Mining interactome modules. Nucleic Acids Research 40:862-865 DOI: 10.1093/nar/gkr967

Degoricija M, Šitum M, Korać J, Miljković A, Matić K, Paradžik M, Terzić IM, Jerončić A, Tomić S, Terzić J. 2014. High NF-אB and STAT3 activity in human urothelial carcinoma: a pilot study. World Journal of Urology 32:1469-1475 DOI: 10.1007/s00345-014-1237-1

Gilmore TD. 2006. Introduction to NF-אB : players, pathways, perspectives. Oncogene 25: 6680-6684 DOI: 10.1038/sj.onc.1209954

Hodges KB, Beltran AL, Davidson DD, Montironi R and Cheng L. 2010. Urothelial dysplasia and other flat lesions of the urinary bladder: clinicopathologic and molecular features. Human Pathology 41:155-162 DOI: 10.1016/j.humpath.2009.07.002

Jenkins GJS, Mikhail J, Alhamdani A, Brown TH, Caplin S, Manson JM, Bowden R, Toffazal N, Griffiths AP, Parry JM, Baxter JN. 2007. Immunohistochemical study of nuclear factor$\kappa \mathrm{B}$ activity and interleukin- 8 abundance in oesophageal adenocarcinoma; a useful strategy 
432

433

434

435

436

437

438

439

440

441

442

443

444

445

446

447

448

449

450

451

452

453

454

455

456

457

458

for monitoring these biomarkers. Journal of Clinical Pathology 60:1232-1238 DOI: 10.1136/jcp.2006.043976

Karst AM, Gao K, Nelson CC, Li G. 2009. Nuclear factor kappa B subunit p50 promotes melanoma angiogenesis by upregulating interleukin-6 expression. International Journal of Cancer 124:494-501 DOI: 10.1002/ijc.23973

Kim H, Park J, Cho Y, Cho C, Kim J, Shin H, Chung DH, Kim SJ, ChunY. 2013. Pathogenic role of HIF-1 $\alpha$ in prostate hyperplasia in the presence of chronic inflammation. Biochimica et Biophysica Acta Molecular basis of disease 1832:183-194 DOI: 10.1016/j.bbadis.2012.09.002

King CC, Sastri M, Chang P, Pennypacker J and Taylor SS. 2011. The rate of NF-кB nuclear translocation is regulated by PKA and A Kinase Interacting Protein 1. PLOS ONE 6: e18713 DOI:10.1371/journal.pone.0018713

Kobayashi H, Kikuchi E, Mikami S, Maeda T, Tanaka N, Miyajima A, Nakagawa K, Oya M. 2014. Long term follow-up in patients with initially diagnosed low grade Ta non-muscle invasive bladder tumors: tumor recurrence and worsening progression. BioMed Central Urology 14:5 DOI: 10.1186/1471-2490-14-5

Lee S, Lee E, Kim S, Jeong P, Cho Y, Yun SJ, Kim S, Kim G, Choi YH, Cha E, Kim W and Moon S. 2012. Identification of Pro-Inflammatory Cytokines Associated with Muscle Invasive Bladder Cancer; the Roles of IL-5, IL-20, and IL-28A. PLOS ONE 7:e40267 DOI:10.1371/journal.pone.0040267

Lee YJ, Moon KC, Jeong CW, Kwak C, Kim HH, Ku JH. 2014. Impact of squamous and glandular differentiation on oncologic outcomes in upper and lower tract urothelial carcinoma. PLOS ONE 9:e107027 DOI: 10.1371/journal.pone.0107027

Lessard L, Karakiewicz PI, Bellon-gagnon P, Alam-fahmy M, Ismail HA, Saad F. 2006. Nuclear localization of nuclear factor- $\kappa \mathrm{B}$ p65 in primary prostate tumors is highly predictive of pelvic lymph node metastases. Clinical Cancer Research 12:5741-5746 DOI: 
459 Levidou G, Saetta AA. 2008. Clinical significance of nuclear factor (NF)- $\kappa B$ levels in urothelial 460 carcinoma of the urinary bladder. Virchows Archives 452:295-304 DOI: 10.1007/s00428$461 \quad 007-0560-y$

462

463

464

465

466

467

468

469

470

471

472

473

474

475

476

477

478

479

480

481

482

483

484

Masilamoni JG, Jesudason EP, Baben B, Jebaraj CE, Dhandayuthapani S and Jayakumar R. 2006. Molecular chaperone $\alpha$-crystallin prevents detrimental effects of neuroinflammation. Biochimica et Biophysica Acta Molecular basis of disease 1762:284-293 DOI: 10.1016/j.bbadis.2005.11.007

Meteoglu I, Erdogdu IH, Meydan N, Erkus M, Barutca S. 2008. NF-KappaB expression correlates with apoptosis and angiogenesis in clear cell renal cell carcinoma tissues. Journal of Experimental \& Clinical Cancer Research 27:53 DOI: 10.1186/1756-9966-27-53

Miller KD, Siegel RL, Lin CC, Mariotto AB, Kramer JL, Rowland JH, Stein KD, Alteri R, Jemal A. 2016. Cancer treatment and survivorship statistics, 2016. CA: A Cancer Journal for Clinicians 66:271-289 DOI: 10.3322/caac.21349

Mukherjee N, Cardenas E, Bedolla R, Ghosh R. 2017. SETD6 regulates NF- $\kappa$ B signaling in urothelial cell survival: Implications for bladder cancer. Oncotarget 8:15114-15125 DOI: 10.18632/oncotarget.14750

Mukherjee N, Houston TJ, Cardenas E and Ghosh R. 2015. To be an ally or an adversary in bladder cancer: the NF-кB story has not unfolded. Carcinogenesis 36:299-306 DOI: $10.1093 /$ carcin/bgu321

Oya M, Takayanagi A, Horiguchi A, Mizuno R, Ohtsubo M, Marumo K, Shimizu N, Murai M. 2003. Increased nuclear factor- $\kappa \mathrm{B}$ activation is related to the tumor development of renal cell carcinoma. Carcinogenesis 24:377-384 DOI: 10.1093/carcin/24.3.377

Öztürk H. 2015. Comparing RECIST with EORTC criteria in metastatic bladder cancer. Journal of Cancer Research and Clinical Oncology 142:187-194 DOI: 10.1007/s00432-015-2022-2

Saccani A, Schioppa T, Porta C, Biswas SK, Nebuloni M, Vago L, Bottazzi B, Colombo MP, Mantovani A, Sica A. 2006. p50 Nuclear factor- $\kappa$ B overexpression in tumor-associated 
485 486

487 488

489

490

491

492

493

494

495

496

497

498

499

500

501

502

503

504

505

506

macrophages inhibits M1 inflammatory responses and antitumor resistance. Cancer Research 66:11432-11440 DOI: 10.1158/0008-5472.CAN-06-1867

Schulz WA. 2006. Understanding urothelial carcinoma through cancer pathways. International Journal of Cancer 119:1513-1518 DOI: 10.1002/ijc.21852

Shannon P, Markiel A, Ozier O, Baliga SN, Wang TJ, Ramage D, Amin N, Schwikowski B and Ideker T. 2003. Cytoscape: a software environment for integrated models of biomolecular interaction networks. Genome Research 13:2498-2504 DOI: 10.1101/gr.1239303

Slattery ML, Mullany LE, Sakoda L, Samowitz WS, Wolff RK, Stevens JR, Herrick JS. 2018. The NF- $\kappa \mathrm{B}$ signalling pathway in colorectal cancer: associations between dysregulated gene and miRNA expression. Journal of Cancer Research and Clinical Oncology 144: 269 DOI:10.1007/s00432-017-2548-6

Sweeney C, Li L, Shanmugam R, Bhat-Nakshatri P, Jayaprakasan V, Baldridge LA, Gardner T, Smith M, Nakshatri H, Cheng L. 2004. Nuclear factor- $\kappa B$ is constitutively activated in prostate cancer in vitro and is overexpressed in prostatic intraepithelial neoplasia and adenocarcinoma of the prostate. Clinical Cancer Research 10:5501-5507 DOI: 10.1158/1078-0432.CCR-0571-03

Szebeni GJ, Vizler C, Kitajka K, Puskas LG. 2017. Inflammation and cancer: Extra- and intracellular determinants of Tumor-Associated Macrophages as tumor promoters. Mediators of Inflammation 2017:1-13 DOI: 10.1155/2017/9294018

Wu D, Wu P, Zhao L, Huang L, Zhang Z, Zhao S, Huang J. 2015. NF-кB expression and outcomes in solid tumors: A systematic review and meta-analysis. Medicine (Baltimore) 94:e1687 DOI: 10.1097/MD.0000000000001687 


\section{Figure 1}

NF-KB signal transduction pathway

Signaling cascade comprises the canonical (classical) and non-canonical (alternate) pathways involving NF-kB family proteins and their target proteins.

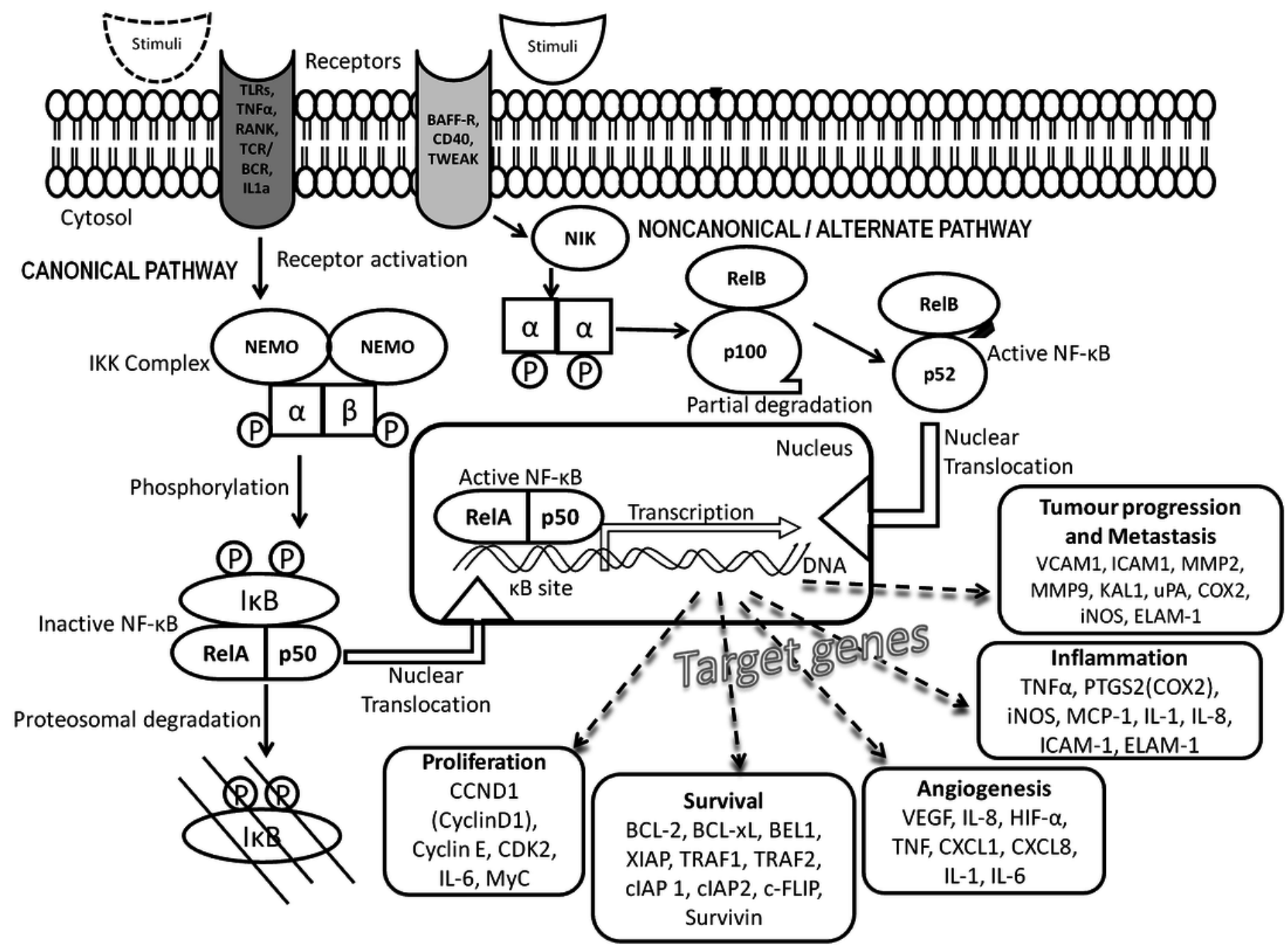




\section{Figure 2}

Cytoscape-PINA4MS result of NF-KB family proteins expression and targets in Urothelial Carcinoma

NF-KB proteins (red bubbles) and their target proteins (green bubbles) expressed or repressed in UC tissues. Size of the bubble represents the expression at mentioned condition. Transparency of the bubble is proportional to the secretion and subsequent expression or suppression. Purple arrows indicate protein-protein interactions whereas magenta arrows indicate the substrate-kinase interactions. All interactions in UC are marked red irrespective of their interaction mode. Proteins with no arrows (stand alone) indicate indirect interaction with the members of the network. Proteins with line fill indicate those with no human protein atlas data. 

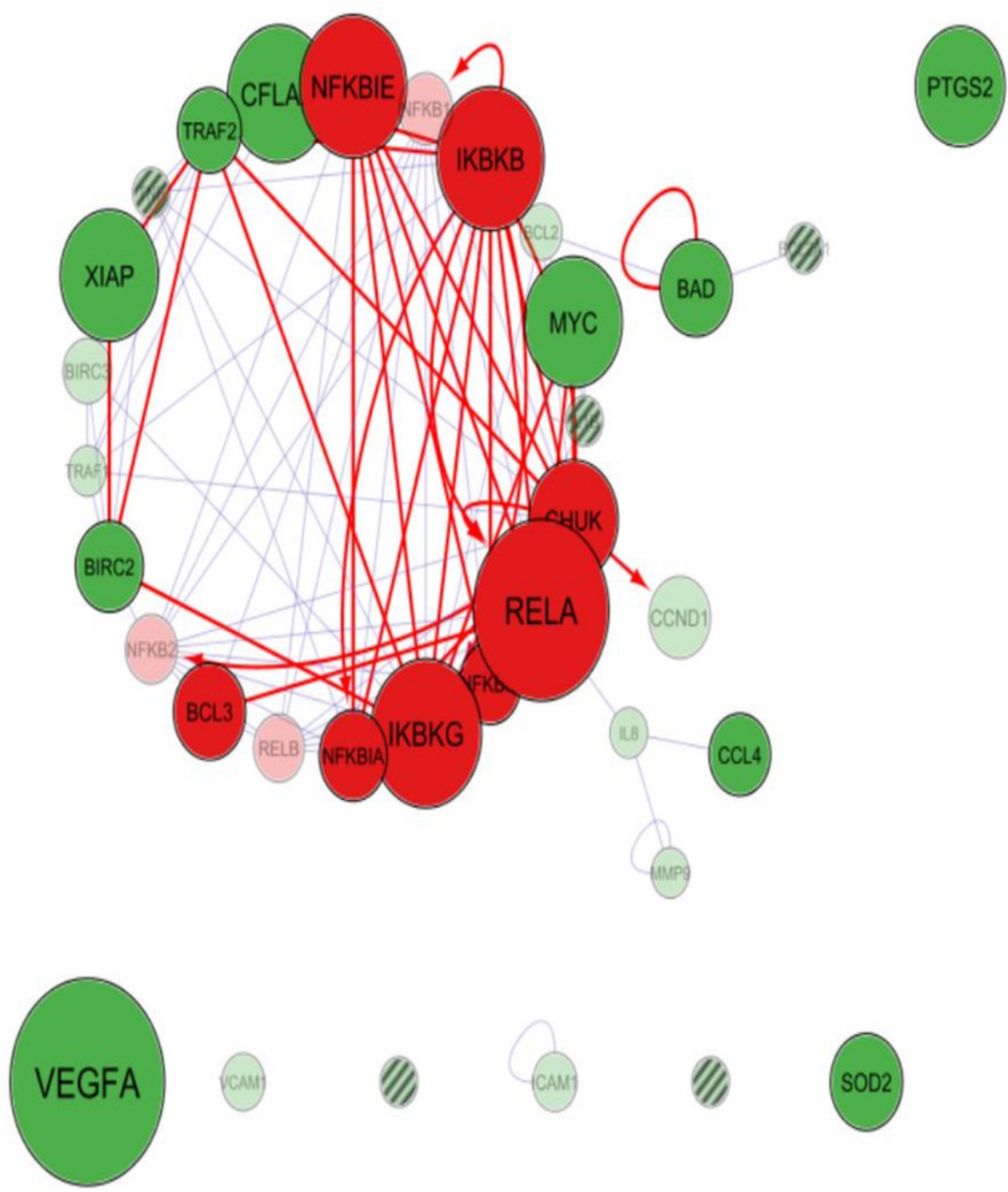


\section{Figure 3}

Cytoscape-PINA4MS result of NF-KB family proteins expression and targets in Normal Urothelium

NF-KB proteins (red bubbles) and their target proteins (green bubbles) expressed in normal urothelial tissues. Size of the bubble represents the expression at mentioned condition. Transparency of the bubble is proportional to the secretion and subsequent expression or suppression. Purple arrows indicate protein-protein interactions whereas magenta arrows indicate the substrate-kinase interactions. All interactions in UC are marked red irrespective of their interaction mode. Proteins with no arrows (stand alone) indicate indirect interaction with the members of the network. Proteins with line fill indicate those with no human protein atlas data. 

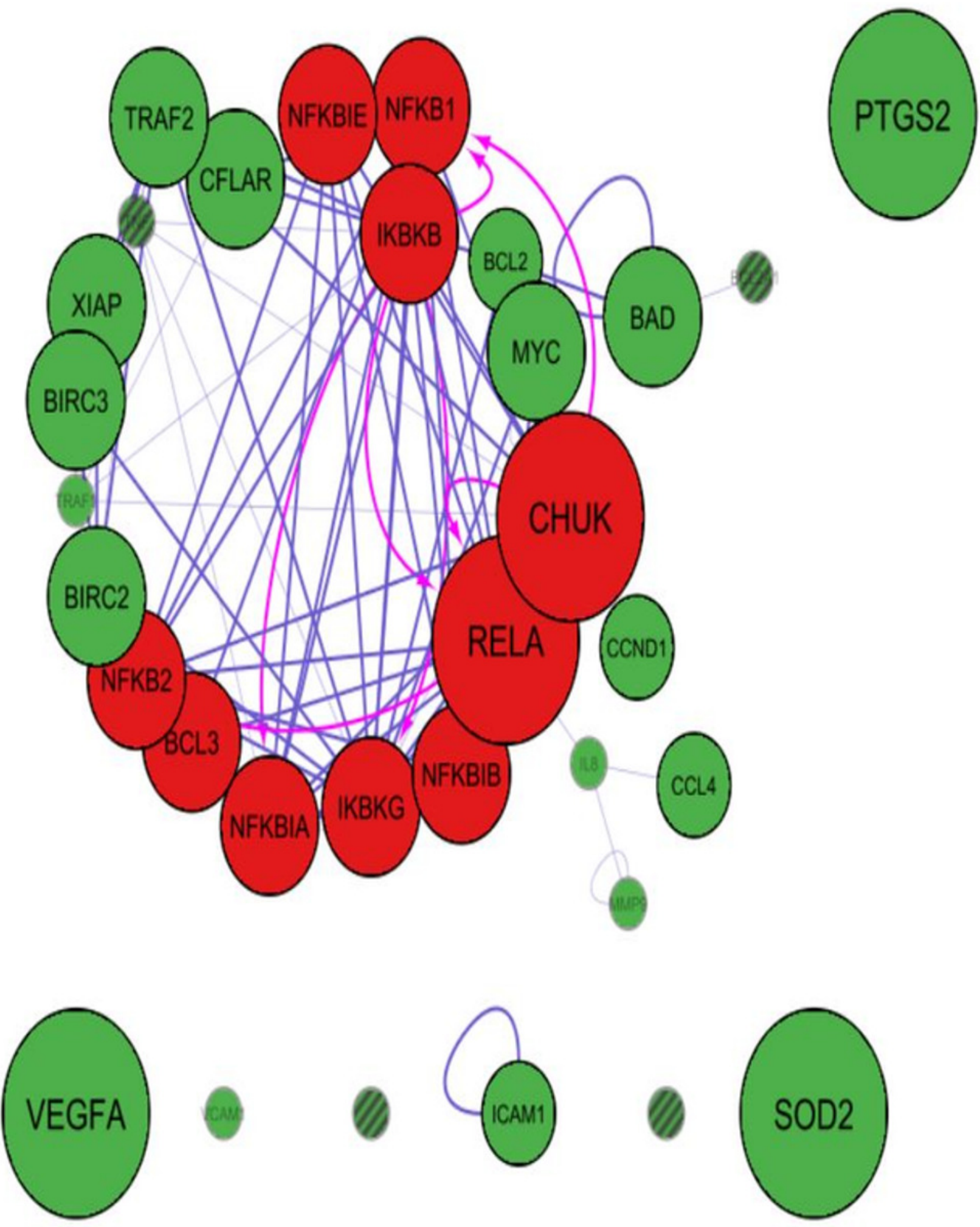


\section{Figure 4}

NF-KB heterodimer expression: High grade urothelial carcinoma

(A) High grade non invasive urothelial carcinoma H\&E $\times 200$. (B) Immunostaining with RelA (p65) showed nuclear positivity (Brown colour) indicated by arrow IHC $\times 200$. (C) NF-KB p50 showed moderate cytoplasmic positivity IHC $\times 200$. Note: adjacent lymphocytes (in-built control) have taken up nuclear staining indicated by arrows. (D) High grade papillary invasive urothelial carcinoma with squamous differentiation H\&E $\times 200$. (E) Immunostaining with RelA (p65) showed nuclear positivity (Brown colour) as indicated by arrows IHC $\times 200$.

(F) NF-KB p50 showed few nuclear and cytoplasmic positivity in squamous regions which are indicated by arrows IHC $\times 200$. (G) High grade invasive urothelial carcinoma $H \& E \times 100$. (H) Immunostaining with RelA (p65) showed nuclear positivity (Brown colour) as indicated by arrows IHC $\times 200$. (I) NF-KB p50 showed extensive cytoplasmic positivity as indicated by arrows $\mathrm{IHC} \times 200$. Scale bar indicates $50 \mu \mathrm{M}$. 
H\&E
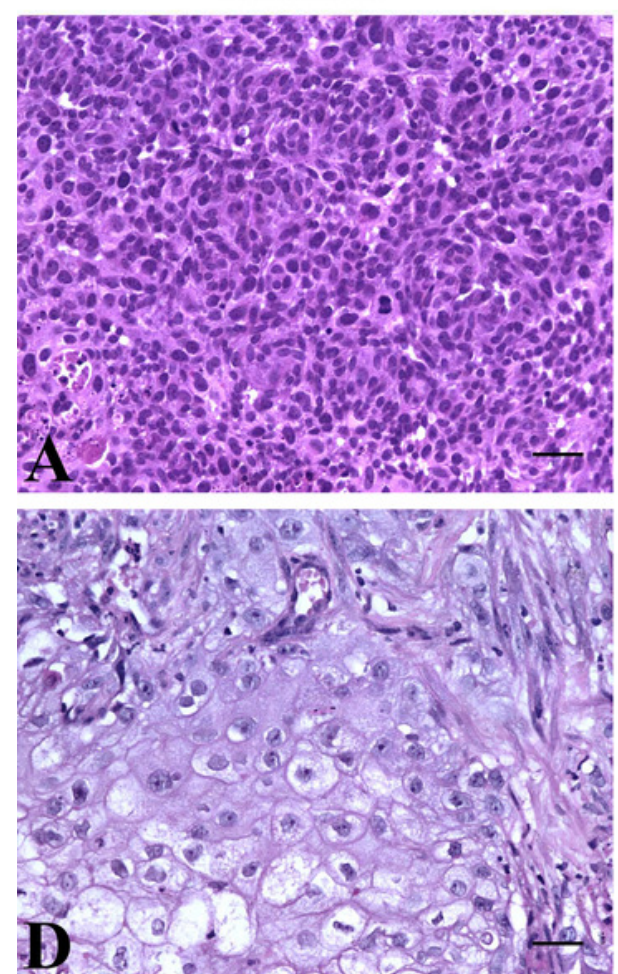

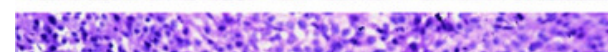

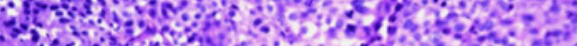

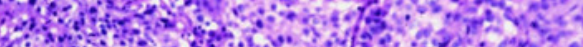

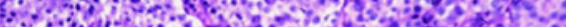

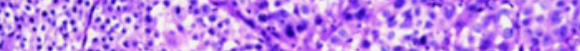

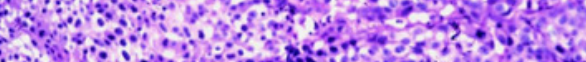

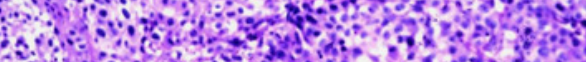

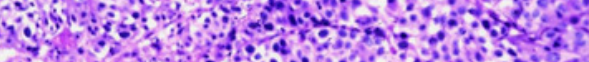

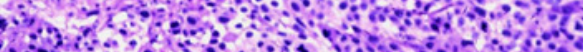

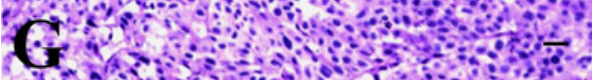

RelA
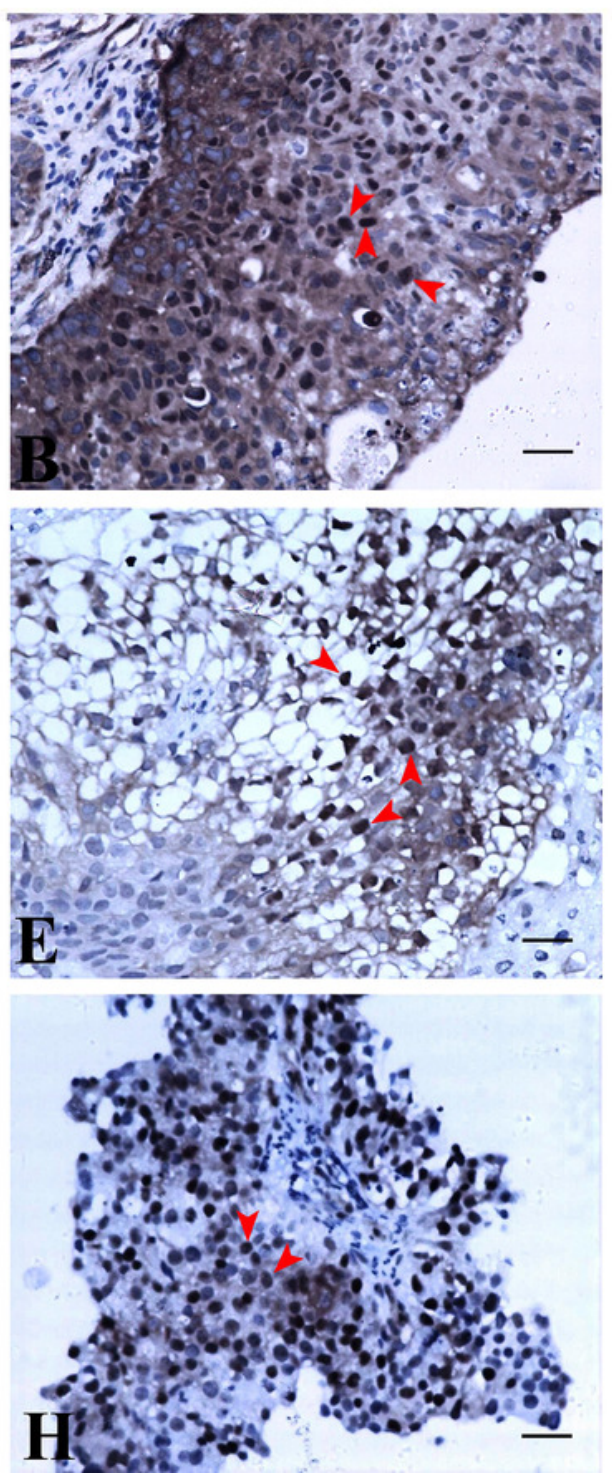

p50
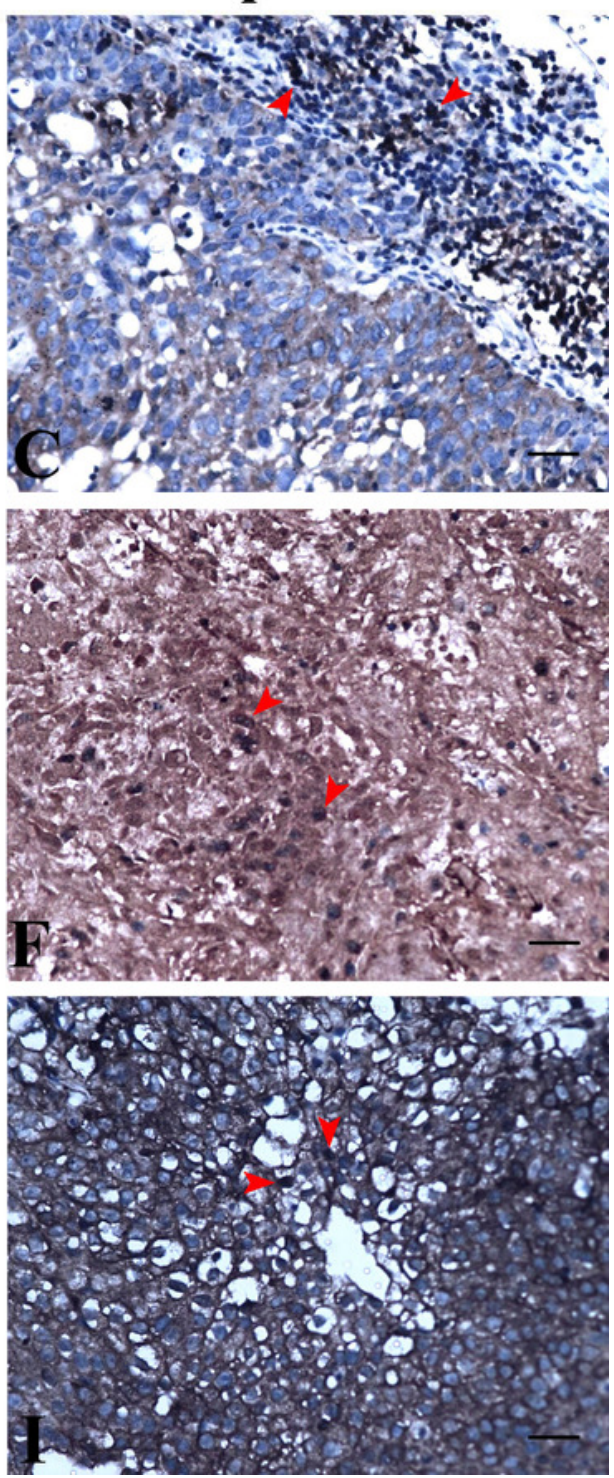


\section{Figure 5}

NF-KB heterodimer expression: Low grade urothelial carcinoma with normal urothelium

(A) Low grade papillary urothelial carcinoma H\&Ex100. (B) Immunostaining with RelA (p65) showed nuclear positivity (Brown colour) IHC $\times 100$. (C) NF-KB p50 showed extensive cytoplasmic positivity IHC $\times 100$. (D) Low grade papillary urothelial carcinoma with tumor infiltration H\&E $\times 40$. (E) Immunostaining with RelA (p65) showed nuclear positivity (Brown colour) IHC $\times 200$. (F) NF-KB p50 showed moderate cytoplasmic positivity IHC $\times 200$. (G) Normal urothelium H\&E $\times 200$. (H) Immunostaining with RelA (p65) showed faint to moderate cytoplasmic positivity (Brown colour) IHC $\times 200$. Note: Lymphocytes (in-built control) have taken up stain indicated by arrows. (I) NF-KB p50 showed moderate cytoplasmic positivity indicated by arrow IHC $\times 200$. Scale bar indicates $50 \mu \mathrm{M}$. 
H\&E
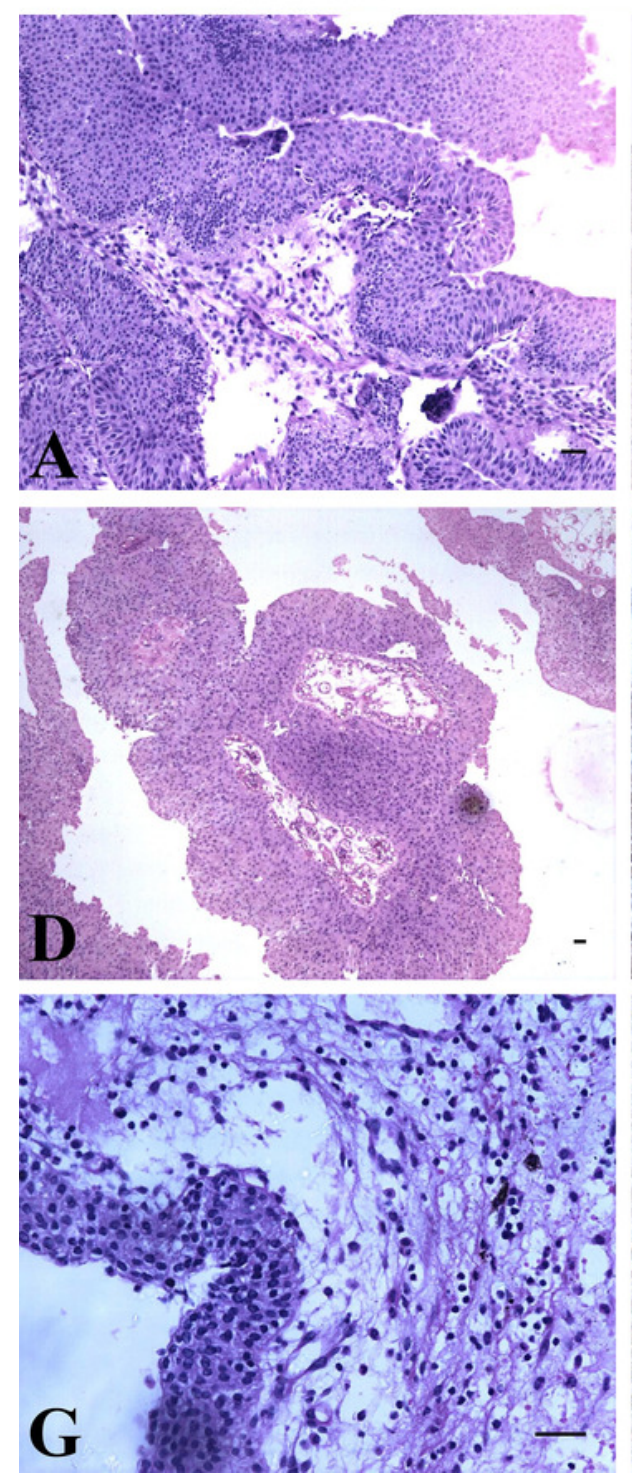

RelA
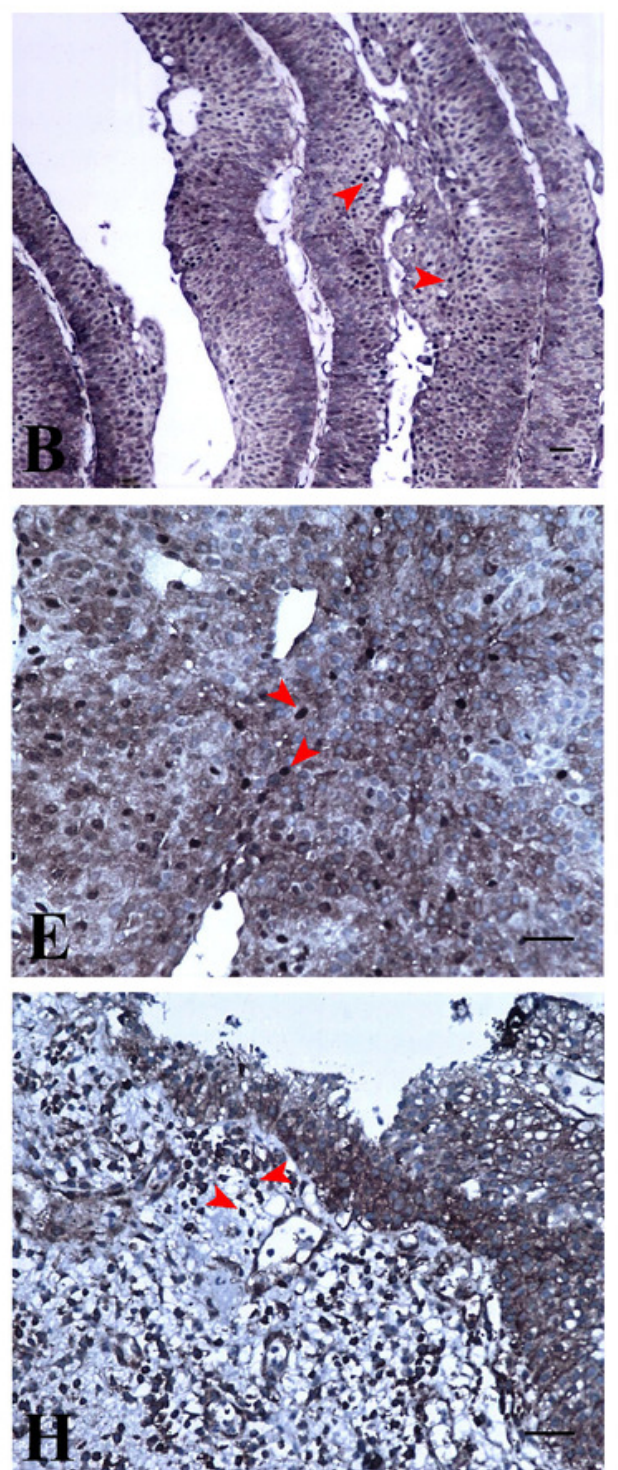

p50
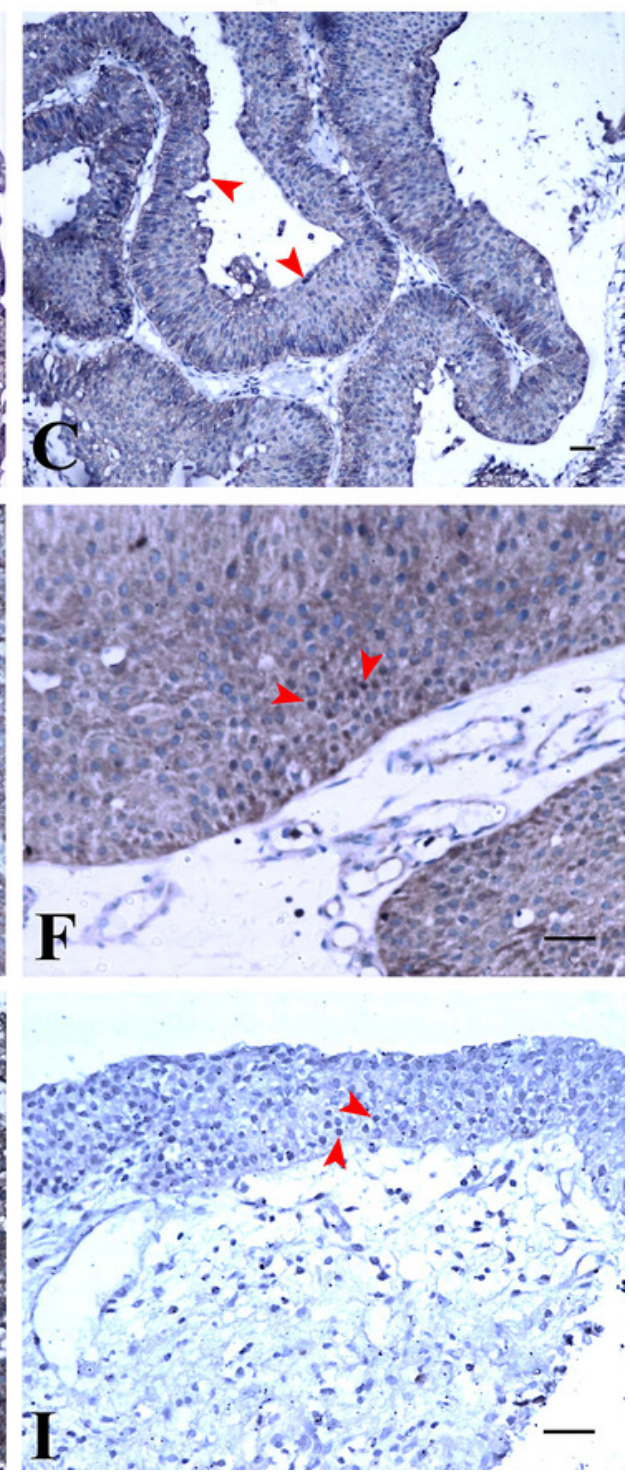


\section{Table $\mathbf{1}$ (on next page)}

Nuclear localization of NF- $\mathrm{kB}$ heterodimers in urothelial tissues: $\mathrm{n}(\%)$ 


\section{Table 1}

2 Nuclear localization of NF- $\kappa B$ heterodimers in urothelial tissues: $n(\%)$

\begin{tabular}{|c|c|c|c|c|c|}
\hline \multirow[b]{2}{*}{ Tissue } & & \multicolumn{2}{|c|}{$\mathrm{NF}-\kappa \mathrm{B}$ heterodimers } & \multirow[b]{2}{*}{$\chi^{2}$ test/ Fisher's test } & \multirow[b]{2}{*}{$p$ value } \\
\hline & & Absent & Present & & \\
\hline Normal & \multirow{2}{*}{ RelA } & $60(100 \%)$ & $0(0 \%)$ & \multirow{2}{*}{39.236} & \multirow{2}{*}{$<0.001$} \\
\hline Cancer & & $31(50.8 \%)$ & $30(49.2 \%)$ & & \\
\hline Normal & \multirow{2}{*}{ p50 } & $60(100 \%)$ & $0(0 \%)$ & \multirow{2}{*}{9.564} & \multirow{2}{*}{$<0.005$} \\
\hline Cancer & & $52(85.2 \%)$ & $9(14.8 \%)$ & & \\
\hline
\end{tabular}

3

4 


\section{Table 2 (on next page)}

Nuclear localization of NF- KB heterodimers in urothelial carcinoma tissues: $\mathrm{n}(\%)$ 


\section{Table 2}

2 Nuclear localization of NF- $\kappa$ B heterodimers in urothelial carcinoma tissues: $\mathrm{n}(\%)$

\begin{tabular}{|c|c|c|c|c|c|}
\hline \multirow[b]{2}{*}{ Cancer grade } & & \multicolumn{2}{|c|}{ NF- $\kappa \mathrm{B}$ heterodimers } & \multirow[b]{2}{*}{$\chi^{2}$ test/ Fisher's test } & \multirow[b]{2}{*}{$\mathrm{p}$ value } \\
\hline & & Absent & Present & & \\
\hline Low & \multirow{2}{*}{ RelA } & $18(64.3 \%)$ & $10(35.7 \%)$ & \multirow{2}{*}{3.755} & \multirow{2}{*}{0.073} \\
\hline High & & $13(39.4 \%)$ & $20(60.6 \%)$ & & \\
\hline Low & \multirow{2}{*}{$\mathrm{p} 50$} & $24(85.7 \%)$ & $4(14.3 \%)$ & \multirow{2}{*}{0.009} & \multirow{2}{*}{1.000} \\
\hline High & & $28(84.8 \%)$ & $5(15.2 \%)$ & & \\
\hline
\end{tabular}

3 


\section{Table 3(on next page)}

Cytoplasmic localization of NF- KB heterodimers in urothelial tissues: $\mathrm{n}(\%)$

Cytoplasmic positivity, I = Low ( $\leq 20 \%) ;$ II = Moderate $(21-60 \%) ;$ III = Extensive ( $\geq 61 \%)$ was based on the staining intensity of the cell cytoplasm with immunoperoxidase positivity 


\section{Table 3}

2 Cytoplasmic localization of NF- $\kappa$ B heterodimers in urothelial tissues: $\mathrm{n}(\%)$

\begin{tabular}{|l|l|l|l|l|c|l|}
\hline Tissue & & I & II & III & $\chi^{2}$ test/ Fisher's test & $\mathrm{p}$ value \\
\hline Normal & \multirow{2}{*}{ RelA } & $24(40 \%)$ & $36(60 \%)$ & $0(0 \%)$ & \multirow{2}{*}{67.944} & $<0.001$ \\
\cline { 4 - 5 } Cancer & & $0(0 \%)$ & $21(34.4 \%)$ & $40(65.6 \%)$ & & \multirow{2}{*}{78.644} \\
\cline { 1 - 3 } Normal & \multirow{2}{*}{$\mathrm{p} 50$} & $24(40 \%)$ & $36(60 \%)$ & $0(0 \%)$ & $<0.001$ \\
\cline { 1 - 4 } & & $0(0 \%)$ & $15(24.6 \%)$ & $46(75.4 \%)$ & & \\
\hline
\end{tabular}

3 Cytoplasmic positivity, I = Low ( $\leq 20 \%)$; II = Moderate $(21-60 \%)$; III = Extensive $(\geq 61 \%)$

4 was based on the staining intensity of the cell cytoplasm with immunoperoxidase positivity.

6

7 


\section{Table 4 (on next page)}

Cytoplasmic localization of NF- KB heterodimers in urothelial carcinoma tissues: $\mathrm{n}(\%)$

Cytoplasmic positivity, I = Low ( $\leq 20 \%) ; I I=$ Moderate $(21-60 \%) ;$ III = Extensive ( $\geq 61 \%)$ was based on the staining intensity of the cell cytoplasm with immunoperoxidase positivity. NOTE: There were no cases in "Low cytoplasmic positivity (I)" category. 


\section{Table 4}

2 Cytoplasmic localization of NF- $\kappa$ B heterodimers in urothelial carcinoma tissues: $\mathrm{n}(\%)$

\begin{tabular}{|c|c|c|c|c|c|}
\hline Cancer grade & & II & III & $\chi^{2}$ test/ Fisher's test & $\mathrm{p}$ value \\
\hline Low & \multirow{2}{*}{ RelA } & $14(50 \%)$ & $14(50 \%)$ & \multirow{2}{*}{5.561} & \multirow{2}{*}{0.030} \\
\hline High & & $7(21.2 \%)$ & $26(78.8 \%)$ & & \\
\hline Low & \multirow{2}{*}{$\mathrm{p} 50$} & $11(39.3 \%)$ & $17(60.7 \%)$ & \multirow{2}{*}{6.028} & \multirow{2}{*}{0.019} \\
\hline High & & $4(12.1 \%)$ & $29(87.9 \%)$ & & \\
\hline
\end{tabular}

3 Cytoplasmic positivity, I = Low ( $\leq 20 \%)$; II = Moderate $(21-60 \%)$; III = Extensive $(\geq 61 \%)$

4 was based on the staining intensity of the cell cytoplasm with immunoperoxidase positivity.

5 NOTE: There were no cases in "Low cytoplasmic positivity (I)" category. 